\title{
The Diamond Model of Open Access Publishing: Why Policy Makers, Scholars, Universities, Libraries, Labour Unions and the Publishing World Need to Take Non-Commercial, Non-Profit Open Access Serious
}

\author{
Christian Fuchs* and Marisol Sandoval** \\ * University of Westminster: Communication and Media Research Institute (CAMRI), Centre \\ for Social Media Research. London, UK. christian.fuchs@uti.at http:/ / fuchs.uti.at \\ ** City University London: Centre for Cultural Policy and Management. London, UK. \\ marisol.sandoval.1@city.ac.uk \\ http://www.city.ac.uk/arts-social-sciences/academic-staff-profiles/dr-marisol-sandoval
}

\begin{abstract}
This reflection introduces a new term to the debate on open access publishing: diamond open access (DOA) publishing. The debate on open access is a debate about the future of academia. We discuss the problems of for-profit academic publishing, such as monopoly prices and access inequalities and point at the limits of contemporary perspectives on open access as they are frequently advanced by the publishing industry, policy makers and labour unions. The article introduces a public service and commons perspective that stresses the importance of fostering and publicly supporting what we term the model of diamond open access. It is a non-profit academic publishing model that makes academic knowledge a common good, reclaims the common character of the academic system and entails the possibility for fostering job security by creating public service publishing jobs. Existing concepts such as "gold open access" have serious conceptual limits that can be overcome by introducing the new term of diamond open access. The debate on open access lacks visions and requires social innovations. This article is a policy intervention and reflection on current issues related to open access (OA) publishing. It reflects on the following questions: What should the role of open access be in the future of academic publishing and academia? How should the future of academic publishing and academia look like? Which reforms of academic policy making are needed in relation to open access publishing? We want to trigger a new level of the open access debate. We invite further reflections on these questions by academics, policy makers, publishers, publishing workers, labour unions, open access publishing associations, editors and librarians.
\end{abstract}

Keywords: open access publishing, diamond model of open access, gold model of open access, green model of open access, academic knowledge, university, commons

\section{Introduction}

Open access (OA) publishing is a big contemporary topic that shapes current academic policy discussions. Academics, universities, corporate publishing houses, non-profit publishers and journals, editors, editorial boards, labour unions representing publishing workers, funding agencies, as well as policy makers are all important actors in this debate. They hold diverse opinions on OA.

We will discuss the problems of for-profit academic publishing, such as monopoly prices and access inequalities. The debate on open access is a debate about the future of academia. We will point out the limits of contemporary perspectives on open access, as they are frequently advanced by the publishing industry, policy makers, and labour unions. We introduce a public service and commons perspective that stresses the importance of fostering and publicly supporting what we term the model of diamond open access. It is a form of nonprofit academic publishing that makes academic knowledge a common good, reclaims the common character of the academic system and entails the possibility of fostering job security by creating public service publishing jobs. Existing concepts such as "gold open access" 
have serious conceptual limits that can be overcome by introducing the new term of diamond open access. The debate on open access lacks visions and requires social innovations.

This article is a policy intervention and reflection on current issues related to open access (OA) publishing. It reflects on the following questions: What should the role of open access be in the future of academic publishing and academia? How should the future of academic publishing and academia look like? Which reforms of academic policy making are needed in relation to open access publishing? We want to trigger a new level of the open access debate and invite further reflections on these questions by academics, policy makers, publishers, publishing workers, labour unions, open access publishing associations, editors and librarians.

We reflect on the status of the for-profit publishing industry and its problems (section 2), the problems of many industry and policy perspectives on OA (section 3 ) and the limits of the predominant labour union perspective on OA (section 4). Based on this discussion, we question the term "gold open access" that in our opinion does more harm than good and suggest a conceptual differentiation between diamond open access and corporate open access (section 5). Finally, we draw some conclusions (section 6).

\section{The Corporate Publishing Industry}

The corporate academic publishing industry has increasingly come under attack. Its critics say that it commodifies academic knowledge; restricts access for individuals and institutions with less financial resources, especially in poor countries; charges high access fees; privatizes the knowledge produced within publicly funded research; exploits the free labour of academics who work as unpaid reviewers, editors, editorial board members and authors. Another point of criticism is that the combination of these tactics results in high profit rates in the academic publishing industry.

To date 13770 scholars have signed a boycott statement against Elsevier that says that this publisher charges "exorbitantly high prices for subscriptions to individual journals"1. Data for a selected sample of large academic publishing houses (see table 1) confirms that the rate of profit tends to be high in this industry. The average rate of profit in our sample is $18.9 \%$. In comparison, the most profitable global company in 2012 Exxon Mobil had a rate of profit of 10.7\% (data source: Forbes 2000, 2013 list). The rate of profit of Wal-Mart, the company with the worldwide highest sales in 2012 was 3.6\% (data source: Forbes 2000, 2013 list).

\begin{tabular}{|l|l|l|l|}
\hline Publisher & Revenues & Profit & Rate of Profit \\
\hline Reed Elsevier & 6,116 million $£$ & 1,089 million $£$ & $21.7 \%$ \\
\hline Springer & 1,551 million $€$ & 260 million $€$ & $20.2 \%$ \\
\hline Taylor \& Francis & 1,233 million $£$ & 246 million $£$ & $24.9 \%$ \\
\hline Wiley-Blackwell & 1,783 million US\$ & 197 million US\$ & $12.4 \%$ \\
\hline Wolters Kluwer & 3,603 million $€$ & 476 million $€$ & $15.2 \%$ \\
\hline & & & Average: $18.9 \%$ \\
\hline
\end{tabular}

Table 1: Financial data of selected academic publishers, financial year 2012 (Springer: 2011), data sources (accessed on July 26, 2013):

http://reporting.reedelsevier.com/media/174016/reed_elsevier_ar_2012.pdf http://www.axelspringer.de/dl/14843813/2011 AS AG JA-Bericht_EN.pdf http://www.informa.com/Documents/Investor\%20Relations/2012\%20FY\%20results\%20\%20Press $\% 20$ Release $\% 20-\% 20$ Final.pdf

http://eu.wiley.com/WileyCDA/Section/id-301733.html

http://www.wolterskluwer.com/Investors/Key-Financials/Pages/Financials.aspx\#Yearly

A study by Bergstrom and Bergstrom (2006) found that in the realm of the top ecology journals, for-profit publishers in 2005 charged an average of US $\$ 1.42$ subscription price per page, whereas journals published by non-profit societies and university presses charged an

\footnotetext{
${ }^{1}$ http://thecostofknowledge.com/, accessed on July 26, 2013.
} 
average of US $\$ 0.29$. Higher price didn't mean higher quality, as the non-profit journals tended "to be older, more prestigious, and more highly cited than their for-profit counterparts" (Bergstrom and Bergstrom 2006, 489). The same phenomenon was also found in the research fields of economics, atmospheric science, mathematics, neuroscience and physics (Bergstrom and Bergstrom 2002), which shows that this seems to be a more general trend. These results show that profits in academic publishing tend to be maximized by high subscription fees. "If one automobile manufacturer charged 6 times as much as its competitors for a car of lower quality, almost nobody would buy its product. [...] Journal articles differ in that they are not substitutes for each other in the same way as cars are. Rather, they are complements. Scientists are not satisfied with seeing only the top articles in their field. [...] Because of this lack of substitutability, commercial publishers of established second-rank journals have substantial monopoly power and are able to sell their product at prices that are much higher than their average costs and several times higher than the price of higher quality, non-profit journals" (Bergstrom and Bergstrom 2004).

Brendan J. Wyly (1998) in a case study of the profitability of four academic publishers Kluwer, Elsevier, John Wiley \& Sons, Plenum - found: "As measured by net profit margin, Plenum Publishing was more profitable in 1997 than 491 companies in the S\&P 500, according to Business Week. Reed Elsevier's net margin was higher than 473 of the companies in the S\&P 500 for 1997. Both Plenum and Reed Elsevier had extraordinary net profit margins compared to the periodical publishing industry as a whole, and Wolters Kluwer was near the upper quartile". This case study is an indication for the assumption that listed publishing houses tend to have higher profit rates than listed companies in most other economic branches.

The cultural historian Robert Darnton, who is the Director of Harvard University's Library (the largest university library in the world), argues that the current system of academic knowledge organization has many problems: "We academics provide the content for scholarly journals. We evaluate articles as referees, we serve on editorial boards, we work as editors ourselves, yet the journals force us to buy back our work, in published form, at outrageous prices. Many journals now cost more than $\$ 20,000$ for a year's subscription. The spiraling cost of journals has inflicted severe damage on research libraries, creating a ripple effect: in order to purchase the journals, libraries have had to reduce their acquisitions of monographs; the reduced demand among libraries for monographs has forced university presses to cut back on the publication of them; and the near impossibility of publishing their dissertations has jeopardized the careers of a whole generation of scholars in many fields" (Darnton 2010, 104).

In many countries and universities citations are an important factor of academic career advancement and evaluations. Furthermore citations are also a form of reputational academic capital. A frequently used tool for measuring impact is Thomson Reuters' Web of Science (Science Citation Index, Social Sciences Citation Index, Arts and Humanities Citation Index). Thomson Reuters has for this purpose developed a special whitepaper titled "Using Bibliometrics: A Guide to Evaluating Research Performance with Citation Data" (Thomson Reuters 2008). In this document, Thomson Reuters praises its databases as tools for research evaluations and acknowledges, but never questions, the neoliberal restructuration of academia: "A library faced with collection decisions, a foundation making funding choices, or a government office weighing national research needs must rely on expert analysis of scientific research performance. Increasingly, universities everywhere must demonstrate their special capabilities to a variety of constituencies. For example, in some countries universities that were once run by the government are in the process of becoming private operations. For the first time, these universities must identify a mission, develop a strategy for meeting it, and market themselves to students and supporters - as do all private institutions" (Thomson Reuters 2008, 3).

Journals that are included in Thomson Reuters' indexes have high visibility. But how are journals that are included selected? Thomson Reuters describes the journal selection process the following way: "The journal's basic publishing standards, its editorial content, the 
international diversity of its authorship, and the citation data associated with it are all considered"2. The company does not publish a transparent, objective selection methodology.

\begin{tabular}{|c|c|c|c|c|}
\hline Journal characteristic & $\begin{array}{c}\text { Share } \\
(\mathrm{N}=210)\end{array}$ & $\begin{array}{c}\mathrm{SSCl} \\
(\mathrm{N}=70)\end{array}$ & $\begin{array}{c}\mathrm{SCl} \\
(\mathrm{N}=70)\end{array}$ & $\begin{array}{c}\mathrm{AHCl} \\
(\mathrm{N}=70)\end{array}$ \\
\hline For-profit publishing organization & $149(71.0 \%)$ & $55(78.6 \%)$ & $59(84.3 \%)$ & $35(50 \%)$ \\
\hline Non-profit publishing organization & $61(29.0 \%)$ & $15(21.4 \%)$ & $11(15.7 \%)$ & $35(50 \%)$ \\
\hline Publisher is a company (profit) & $149(71.0 \%)$ & $55(78.6 \%)$ & $59(84.3 \%)$ & $35(50 . \%)$ \\
\hline Publisher is an association (non-profit) & $21(10.0 \%)$ & $7(10 \%)$ & $7(10 \%)$ & $7(10 \%)$ \\
\hline $\begin{array}{l}\text { Publisher is a university press } \\
\text { (non-profit) }\end{array}$ & $23(11.0 \%)$ & $5(7.1 \%)$ & $2(2.9 \%)$ & $16(22.9 \%)$ \\
\hline $\begin{array}{l}\text { Journal is published at a public } \\
\text { university (non-profit) }\end{array}$ & $8(3.8 \%)$ & $0(0 \%)$ & $1(1.4 \%)$ & $7(10 \%)$ \\
\hline $\begin{array}{l}\text { Publisher is a government or other } \\
\text { public institution (non-profit) }\end{array}$ & $6(2.9 \%)$ & $2(2.9 \%)$ & $0(0 \%)$ & $4(5.7 \%)$ \\
\hline $\begin{array}{l}\text { Publisher is a charity or other non-profit } \\
\text { organization (non-profit) }\end{array}$ & $3(1.4 \%)$ & $1(1.4 \%)$ & $1(1.4 \%)$ & $1(1.4 \%)$ \\
\hline Open access journals & $25(11.9 \%)$ & $11(15.7 \%)$ & $5(7.1 \%)$ & $9(12.9 \%)$ \\
\hline Closed access journals & $185(88.1 \%)$ & $59(84.3 \%)$ & $65(92.9 \%)$ & $61(87.1 \%)$ \\
\hline $\begin{array}{l}\text { Share of OAJs without author fees in all } \\
\text { OAJs }\end{array}$ & $21(84 \%)$ & $11(100 \%)$ & $1(20 \%)$ & $9(100 \%)$ \\
\hline $\begin{array}{l}\text { Share of OAJs with author fees in all } \\
\text { OAJs }\end{array}$ & $2(8 \%)$ & $0(0 \%)$ & $2(40 \%)$ & $0(0 \%)$ \\
\hline $\begin{array}{l}\text { Share of green "open" access journals } \\
\text { (no fees, but opening of articles only a } \\
\text { year after publishing) in all OAJs }\end{array}$ & $2(8 \%)$ & $0(0 \%)$ & $2(40 \%)$ & $0(0 \%)$ \\
\hline $\begin{array}{l}\text { Share of OAJs published by non-profit } \\
\text { organizations in all OAJs }\end{array}$ & $21(84 \%)$ & $8(72.7 \%)$ & $4(80 \%)$ & $9(100 \%)$ \\
\hline $\begin{array}{l}\text { Share of open access journals published } \\
\text { by for-profit organizations in all OAJs }\end{array}$ & $4(16 \%)$ & $3(27.3 \%)$ & $1(20 \%)$ & $0(0 \%)$ \\
\hline $\begin{array}{l}\text { Share of closed access journals } \\
\text { published by for-profit organization in all } \\
\text { journals }\end{array}$ & $145(78.4 \%)$ & $63(90 \%)$ & $63(90 \%)$ & $44(62.9 \%)$ \\
\hline $\begin{array}{l}\text { Share of closed access journals pub- } \\
\text { lished by non-profit organizations in all } \\
\text { journals }\end{array}$ & $40(21.6 \%)$ & $7(10 \%)$ & $7(10 \%)$ & $26(37.1 \%)$ \\
\hline
\end{tabular}

Table 2: Characteristics of a random sample of journals indexed in the Arts and Humanities Citation Index (AHCl), Science Citation Index (SCl), Social Sciences Citation Index (SSCI), N=210

We have conducted an analysis of journal characteristics of a random selection of journals in the Science Citation Index (3751 journals indexed in 2013), the Social Sciences Citation Index (3121 journals) and the Arts and Humanities Citation Index (1728 journals) (see table 2). From a total of 8600 journals we took a randomly selected sample of 210 journals, comprised of 70 journals from each of the three databases. The random sample consisted of $2.44 \%$ of the total journals indexed in $\mathrm{AHSCl}, \mathrm{SCl}$ and $\mathrm{SSCl}$. We accessed the databases' journal master lists, in which the indexed journals are listed and each holds a unique identifying number ranging from 1 to $\mathrm{N}$, where $\mathrm{N}$ is the number of indexed journals. This allowed us to use a random number generator for selecting 70 journals per database by random selection. Table 2 presents an analysis of the journals' characteristics. Journals that are published in a closed format, but offer open access as paid option (e.g. Sage Open, SpringerOpen, Taylor \& Francis Open) were not considered as open access, but as closed access models because open access is not the automatic standard publishing model, but an option. The Directory of Open Access Journals (DOAJ) has taken the same path on how to define its included journals and excludes journals that only have an open access option. A genuine open access

${ }^{2}$ http://wokinfo.com/essays/journal-selection-process/, accessed on July 26, 2013. 
journal publishes all articles open access. The DOAJ argues that open access journals should be defined as "journals that use a funding model that does not charge readers or their institutions for access" 3 . An open access option does not make a journal an open access journal.

In the analysed sample, $88.1 \%$ of the journals were closed access and $11.9 \%$ open access journals. $71.0 \%$ of the analysed journals were published by for-profit organizations as opposed to $29.0 \%$ non-profit organizations. This shows that open access journals are a small minority in the analysed sample and that journals published by non-profit organizations are also a minority. The data indicates that especially closed access journals and journals published by for-profit companies get indexed in the Arts and Humanities Citation Index, the Science Citation Index and the Social Sciences Citation Index. The share of journals published by non-profit organizations is relatively large in the Arts and Humanities (50\%) and very low in the Sciences $(15.7 \%)$. It is $21.4 \%$ in the Social Sciences. The share of open access journals is $15.7 \%$ in the Social Sciences, $12.9 \%$ in the Arts and Humanities and $7.1 \%$ in the Sciences. The representation of OAJs is very low in all three samples and as a result also in the combined sample.

The typical OAJ that can be found in the sample does not use author-fees and is nonprofit: $84 \%$ of the analysed OAJs do not use author fees and are not "green OAJ" (=no author fees, holding time of typically a year before the articles are opened). $84 \%$ of the analysed OAJs are published by non-profit organizations. In contrast, $78.4 \%$ of the analysed closed access journals are published by for-profit organizations.

The overall result is that the analysed sample was strongly dominated by closed access journals that sell article content as a commodity and thereby make monetary profits, whereas open access journals that typically are published by non-profit organizations and do not use author fees are a small minority in the analysed sample. If an analysis of all journals indexed by ISI Thomson showed a similar result as the one we obtained in our sample that represents $2.44 \%$ of the 8600 journals indexed in the $\mathrm{AHCl}$, the $\mathrm{SCl}$ and the $\mathrm{SSCl}$ in 2013 , then this would mean that ISI Thomson's three indexes would in their current form not advance open access journals, but would rather marginalize this type of publication in the academic world.

Critics of our argument could say that the reason why OAJs are underrepresented in citation indexes is that they are less professional, are of less quality, attract less interest, and therefore have fewer citations. Given that many scholars and institutions consider ISI Thomson's indexes as indicative of high reputation, they tend to rely on, read and cite predominantly articles listed in these databases. As a result, there is a vicious cycle of reinforcing reputation for journals published in for-profit journals, whereas open access journals and articles are structurally disadvantaged. This effect is known as the Matthew effect (Merton 1968, 1988): those journals rich in citations and reputation indexed in ISI Thomson's databases get richer over time, whereas Open Access Journals are, as we have shown, much less indexed in these databases and therefore have less opportunities for advancing their reputation and citations. The only solution for overcoming these structural limits is a revolution in academic indexing and reputation-making that dismantles the influence that ISI Thomson's citation databases have and substitutes them by databases and indexes supplied by non-profit organizations, such as the Directory of Open Access Journals (DOAJ). In practical terms this could mean to not count articles indexed in ISI Thomson's and other corporate databases for tenure reviews and research evaluations, but to only rely on articles published in journals listed in the DOAJ. One could furthermore think of developing a new database that indexes open access articles.

\footnotetext{
${ }^{3}$ http://www.doaj.org/doaj?func=loadTemplate\&template=about\&uiLanguage=en\#definitions, accessed on August $21,2013$.
} 


\section{The Policy and Industry Perspective: Gold Open Access as New Business Model}

The OA policy debate has recently gained new impetus: The UK government in 2012 accepted the recommendations of the Finch Report (Working Group on Expanding Access to Published Research Findings 2012). This report tends to give a strong stress to defining open-access as models that do not charge readers, but authors: "Open access journals turn the subscription-based model on its head: instead of relying on subscription revenues provided by or on behalf of readers, most of them charge a fee to authors, generally known as an article processing or publishing charge (APC), before an article is published. Access for readers is then free of charge, immediately on publication, and with very few restrictions on use and re-use. The number of journals operating in this way has grown fast in recent years, albeit from a low base" (Working Group on Expanding Access to Published Research Findings 2012, 6).

It stresses the importance of revenue generation for publishers: "The key point here is that no form of publishing is cost-free; and the key requirement is therefore that publishers whether commercial or not-for-profit - should be able to generate revenues to meet the costs of those services they provide that are valued by researchers and their readers" (Working Group on Expanding Access to Published Research Findings 2012, 61f).

The Finch Report recommends that "a clear policy direction should be set towards support for publication in open access or hybrid journals, funded by APCs, as the main vehicle for the publication of research, especially when it is publicly funded" (Working Group on Expanding Access to Published Research Findings 2012, 7). Research Councils UK (2012) supports the main recommendations and has adopted a policy that allows grant holders to apply for article processing charges (APCs).

Also the European Commission has adopted a model that stresses APCs for its Horizon 2020 research funding programmes. It has taken over the distinction between gold and green open access: "'Gold' open access (open access publishing): payment of publication costs is shifted from readers (via subscriptions) to authors. These costs are usually borne by the university or research institute to which the researcher is affiliated, or by the funding agency supporting the research. 'Green' open access (self-archiving): the published article or the final peer-reviewed manuscript is archived by the researcher in an online repository before, after or alongside its publication. Access to this article is often delayed ('embargo period') at the request of the publisher so that subscribers retain an added benefit" (European Commission 2012, 5). The EU argues that both models will be supported in Horizon 2020: "In Horizon 2020, both the 'Green' and 'Gold' models are considered valid approaches to achieve open access" (European Commission 2012, 9).

The UK Publishers Association (2012) says that it was involved in the UK policy debate and that it "warmly welcomes and supports the 'balanced package' of recommendations for extending access to research outputs within the UK that are set out in the Finch report released today. [...] We feel confident in confirming that the industry we represent will endorse and work to implement the recommendations of Finch as a balanced package of measures to extend access. Practical outcomes will include: setting up workflows for the APCs (article publishing charges) that will fund so-called Gold Open Access (OA) (whereby publishing is paid for by the author or funding body); extending existing licences for the universities, research institutes and the health sector; enabling free walk-in access via the public libraries network; supporting authors with their manuscript deposit mandates".

More than 50 publishing organizations, including Elsevier, Emerald, John Wiley \& Sons, Nature Publishing Group, Springer, Taylor \& Francis and World Scientific, support a statement issued by the International Association of Scientific, Technical \& Medical Publishers (2013) that calls for "sustainable open access": "We support any and all sustainable models of access that ensure the integrity and permanence of the scholarly record. Such options include 'gold' open access, whereby publication is funded by an article publishing charge paid by the author or another sponsor, a subscription-based journal, or any one of a number of hybrid publishing options. [...] Gold open access provides one approach toward our 
shared goal of expanding access to peer-reviewed scientific works and maximizing the value and reuse of the results of scientific research".

The discussion shows that policy makers, research funding institutions and the publishing industry tend to agree that supporting and implementing open access journals (OAJ) is an important task. At the same time these stakeholders put a strong stress on one specific model: the one that uses APCs. The publishing industry hopes to develop new capital accumulation models based on APCs and therefore speaks of the need of "sustainable open access" that allows "maximizing the value". What such statements mean is that the publishing industry supports open access if it can make monetary profits from it. The discussion indicates that the publishing industry's associations engage in strong lobbying in order to ensure that new open access models and policies do not threaten the industry's high profits.

What is the reality of open access publishing? Are models that use APCs really dominant, as often claimed in policy debates? Peter Suber (2013), a key person in the open access movement and co-founder of the Directory of Open Access Journals (DOAJ, http://www.doaj.org), argues that only $31 \%$ of the almost 9000 journals listed in the DOAJ use APCs. Statistics provided by DOAJ confirm that in September 2013, out of a total of 9891 journals listed in the DOAJ, $6527(66.0 \%)$ had no article processing charges, 3160 $(32.0 \%)$ had such charges and for 204 journals $(2.0 \%)$ no further information of the use of such charges was available ${ }^{4}$.

Walters and Lindvill (2011) analysed 663 OAJs in biology, computer science, economics, history, medicine and psychology and found that only $29 \%$ use APCs. We have analysed the share of OAJs with APCs in selected subject areas in the Social Sciences and Humanities (see table 3).

\begin{tabular}{|c|c|c|c|}
\hline Subject area & Number of OAJ & $\begin{array}{c}\text { Journals with } \\
\text { APCs }\end{array}$ & $\begin{array}{c}\text { Journals without } \\
\text { APCs }\end{array}$ \\
\hline Media and Communication & 127 & $12(9.4 \%)$ & $115(90.6 \%)$ \\
\hline Sociology & 166 & $21(12.7 \%)$ & $145(87.3 \%)$ \\
\hline Economics & 225 & $54(24 \%)$ & $171(76 \%)$ \\
\hline Political Science & 206 & $12(5.8 \%)$ & $194(94.2 \%)$ \\
\hline History & 256 & $6(2.3 \%)$ & $250(97.7 \%)$ \\
\hline Philosophy & 215 & $8(3.7 \%)$ & $207(96.3 \%)$ \\
\hline Anthropology & 103 & $12(11.7 \%)$ & $91(88.3 \%)$ \\
\hline Business and Management & 352 & $99(28.1 \%)$ & $253(71.9 \%)$ \\
\hline Gender Studies & 40 & $1(2.5 \%)$ & $39(97.5 \%)$ \\
\hline Education & 644 & $64(10.0 \%)$ & $580(90.0 \%)$ \\
\hline Average & & $11.0 \%$ & $89.0 \%$ \\
\hline
\end{tabular}

Table 3: Share of open access journals with article-processing charges (APCs) in selected subject areas in the Social Sciences and Humanities, data source: http://www.doaj.org, accessed on July 4, 2013

The share of APC-based journal ranges between 2.3\% in History at the lower end and $28.1 \%$ in Business and Management at the upper end. The average share of APC-based journals is $11.0 \%$. Comparing these data to the ones provided by Peter Suber and the DOAJ suggests that the use of APCs tends to be much less in the Social Sciences and Humanities than in the natural and engineering sciences. It also indicates that within the Social Sciences and Humanities, the more administrative and conservative subjects, such as Economics and Business/Management Studies, are more likely to use APCs than the more critical fields. But even Economics and Business/Management Studies both have APC rates of less than $30 \%$ of the journals. The data reveal that claims that APCs are the most important model of OAJs are flawed. Given that claims and reality diverge, one must assume that there are other reasons, as e.g. the profit interests of the publishing industry, that result in the overestimation of the importance of APCs in the open access-publishing world.

\footnotetext{
${ }^{4}$ Data source: http://www.doaj.org/doaj?func=byPublicationFee\&uiLanguage=en (accessed on September 8, 2013).
} 
The analysed policy documents by Research Councils UK (2012), the European Commission (2012) as well as the Finch Report (Working Group on Expanding Access to Published Research Findings 2012) tend to define Gold OA as immediate online publishing of articles without access charges, but with author fees (APCs). The distinction between green, gold, gratis and libre OA stems from Peter Suber (2012). Suber (2012) defines Gold OA as literature that is "digital, online, free of charge, and free of most copyright and licensing restrictions" (p. 4) and is "delivered by journals" (p. 6), whereas Green OA is "delivered by repositories" (p. 6). "The gratis/libre distinction is about user rights or freedoms, while the green/gold distinction is about venues or vehicles" (Suber 2012, 67). Gratis OA removes "price barriers", libre OA removes "at least some permission barriers" (Suber 2012, 6).

Peter Suber includes both for-profit and non-profit models as well as publicly subsidized and APC-based models in the category of gold OA: "Some OA journals have a subsidy from a university, library, foundation, society, museum, or government agency. Other OA journals charge a publication fee on accepted articles, to be paid by the author or the author's sponsor (employer or funder). The party paying the subsidy or fee covers the journal's expenses and readers pay nothing" (Suber 2012, 136).

The problem of the above-mentioned policy documents is that they reduce the definition of gold OA to the APC-model and thereby foster the "most common myth about gold OA [...] that all OA journals charge 'author fees' or use an 'author-pays' business model" (Suber $2012,137 f)$. Whereas these policy documents disregard the existence of non-profit OA models and those that do not use author fees, Suber's definition of gold OA is so broad that it does not allow an adequate distinction between for-profit and non-profit models. Predatory OAJs that are in this business all for the money are defined by the same category as nonprofit journals run by communities of committed scholars and editorial teams.

A phenomenon that tends to be associated with OAJs that charge APCs is the emergence of predatory OAJ. Jeffrey Beall (2012) who operates a website that documents questionable practices of OAJ (http://scholarlyoa.com) writes that the following criteria are often characteristic of predatory OAJ:

- Lack of editorial information,

- The publisher operates many OAJs that tend to be funded by APCs,

- The journal sends spam calls for papers or review requests in order to publish as many articles as possible, which means higher revenues from APCs.

An example: Bentham Science publishes 242 open access journals that all have the name "Open X Journal", are situated in all imaginable academic fields, all use the same publication interface, and tend to hide information about publication fees (http://www.benthamscience.com/open/, accessed on July 4, 2013). The APC for publishing a research article is US\$ 800 in a "Group One" journal (e.g. Open Applied Physics Journal, Open Astronomy Journal, Open Biology Journal, Open Biotechnology Journal, Open Cancer Journal, Open Communication Journal, Open Ethics Journal, Open Political Science Journal, Open Urban Studies Journal) and US\$ 250 in a "Group Two" journal (e.g. Open Horticulture Journal, Open Law Journal, Open Nanomedicine Journal, Open Numerical Methods Journal, Open Sociology Journal) (http://www.benthamscience.com/open/a-z.htm, accessed on July 4, 2013). The group two APC is according to Bentham only available for a limited time period. The publisher justifies the use of APCs the following way: "Open access publishing is not without costs. To provide open access, Bentham OPEN journals partly defrays the expenses of peer review, journal production, and online hosting and archiving from authors and their research sponsors by charging a publication fee for each article they publish" 5 .

Most journals are specialized on certain subfields within academic disciplines and fields. In Media and Communication Studies there are e.g. specializations of journals such as New Media \& Society; The Information Society; Political Communication; Journal of Health Communication; Journal of Advertising Research; Telecommunications Policy; Media Psychology; Media, Culture \& Society; Journalism Studies; Games and Culture; Communication, Capitalism \& Critique, etc. There are specialized scholars who engage in the journals' communities

\footnotetext{
${ }^{5}$ http://www.benthamscience.com/open/policy.htm, accessed on July 4, 2013.
} 
as editors, board members and reviewers. Bentham has very general journal focuses, such as "Open Communication Journal". It is also common that these journals state that they publish articles "in all areas" of a discipline. These practices are indicative of a business model that tries to attract and publish as many articles as possible in order to maximize profits.

Predatory OAJs undermine quality mechanisms such as peer-review in academic publishing. They charge authors and therefore privilege wealthy universities, grant holders, scholars with high salaries and academia in Western countries and discriminate against resource-poor universities as well as schools, departments, scholars and academia in poorer countries. The general publication focus of predatory OAJs does not foster the creation and sustenance of academic communities and identities that are organized around a common academic project that reflects the research interest of the peer group. The main goal is economic profit by all means rather than academic communication, discussion and collaboration. Predatory OAJs have the potential to destroy academic communities by a specific mode of commodification of journal articles, in which an exchange of money for publication space takes place between the publisher and authors.

We have argued in this section that:

a) it is mistaken to assume that OAJs with APCs are dominant,

b) that a broad definition of gold OAJs ideologically disguises the differences between forprofit and non-profit models and invites ideological abuse of this category by for-profit publishers,

c) that for-profit OAJs with APCs tend to foster predatory publishing.

\section{The Union Perspective: High-Quality Paid Employment in the Corporate Pub- lishing Industry}

Policy-makers and research councils tend to perceive OAJs from the perspective of scholars and the publishing possibilities that these journals offer. Corporate publishers mainly have a monetary interest in OAJs. Labour unions that represent knowledge workers bring a different perspective to the discourse. They are predominantly concerned with working conditions in the publishing industry.

The UK-based National Union of Journalists (NUJ) argues that the publishing industry "is dominated by a small number of multinational companies whose only rationale is profit" (National Union of Journalists 2012, 1), which has led to the lowering of "editorial staff wages" so that "trained British and Irish editors sometimes end up being paid less than the minimum wage, while working in cultures deeply hostile to collective bargaining. Meanwhile, skills have been disregarded, work has been outsourced to cheaper countries, and quality has suffered" (NUJ 2012, 2) ${ }^{6}$. The NUJ shares concerns about high subscription fees and limited access and describes the extensive discussion about OAJs as an "academic spring" (NUJ 2012, 1) that reacts to the industry's monopoly-capitalist structures. The NUJ therefore speaks of "the revolt of academics and universities against the soaring costs of (especially) journal subscriptions" (NUJ 2012, 1).

This means that the NUJ stresses that monopoly structures in publishing undermine both the interests of editorial workers and academics. However, the NUJ fears that OA solves the problem of high subscription fees at the expense of editorial workers by fostering models that outsource and crowdsource the professional work of copyeditors, translators, commissioning editors, editorial assistants and proof-readers to voluntary work conducted by academics, $\mathrm{PhD}$ and other students or department secretaries. It therefore stresses the importance of editorial quality in academic publishing: "But there is no free lunch. The value for readers that editorial staff add - through the production of clear, consistent, well edited and presented, and thoroughly checked learned articles and books - must be recognised and paid. [...] But open access can only fulfil its aims if it is open access to well produced publications. [...] The NUJ believes that publishers must make a new commitment to editorial quality if they are to argue successfully for their role in the academic process" (NUJ 2012, 2).

\footnotetext{
${ }^{6}$ See also the video of the NUJ debate on "Open Access and Editorial Quality":

http://www.youtube.com/watch?v=uyeRAhxcPjQ\&feature=youtu.be (accessed on September 8, 2013).
} 
The corporate publishing industry's practices harm both scholars and editorial workers: They strive for high profits-rates that result in high subscription fees, the commodification of academic knowledge, the exploitation of the academics' free labour and deteriorating working conditions of those employed in the academic publishing industry.

Union strategies can either be more immanent or more transcendent:

- Immanent strategies struggle for higher wages within capitalist companies in order to empower waged workers.

- Transcendent strategies want to create new models of production and work that function beyond the logic of the exploitation of labour and monetary profits.

The problem of immanent politics is that projects for alternative forms of organization that are non-profit in character are rejected with the aim of increasing wages and working conditions, but at the same time capital interests that are challenged by these projects are also defended.

The problem of transcendental politics is that a) any alternative project is prone to new strategies of commodification that just posit new forms of exploitation and monopoly creation, and b) the establishment of alternatives has to start within capitalism and therefore requires resources that are not readily provided because alternatives do not embrace business models and are also often critical of the state. As a consequence, the history of alternative media is a history of critical content, but also a history of precarious voluntary labour and resource precariousness (Sandoval and Fuchs 2010).

The discussion shows that establishing alternatives to corporate monopolies and oligopolies in academic publishing that enable free access to academic knowledge and high-quality editorial work under good working conditions is facing an antagonism between:

a) the pure immanence of improving working conditions within corporate publishing houses without any transcendental project and

b) the pure autonomist transcendence of establishing alternative projects that lack resources and ignore the immanent need to obtain money for starting and maintaining alternatives.

The problem is that strategies that either rely purely on the logic of money (higher wages as ultima ratio) or purely neglect money (total refusal as ultima ratio) are bound to fail. A different approach is needed - the one of immanent transcendence: we take the position that a sustainable future of academic publishing can best be achieved if publishing jobs become public service jobs and academic knowledge a common good that is published by non-profit organizations that obtain state funding and thereby employ publishing workers.

The problem that the NUJ and other unions face when discussing OAJs and working conditions in the publishing industry is that even though they are recognizing that the corporate model is causing problems, the everyday working conditions of the editorial labour they represent depends on publishing corporations' revenues. In capitalism, corporations often are the only established ways of organizing wages for editorial workers that guarantee a living. For unions it is especially difficult to argue for establishing non-corporate alternatives in the realm of publishing because the vanishing of publishing corporations immediately threatens the workplaces and survival of publishing workers. This threat should in our view however not be answered by a conservative defence of publishing corporations and a pragmatism without a vision of academic life and work beyond capitalism. Quite on the contrary, the lack of alternatives today requires thinking about how to establish alternative publishing projects without corporate profits and the exploitation of labour, but with good working conditions. But how can such projects be achieved?

The lack of political vision and trust in the possibility of alternatives is expressed in the NUJ's document by the fact that in the end it argues in a manner that is not dissimilar from the policy and industry perspective: "one possible solution we have proposed would be for researchers to include the cost of a fairly funded publishing system in their grant applications - simple and a small increase on budgets. [...] The NUJ believes that publishers must make a new commitment to editorial quality if they are to argue successfully for their role in the academic process" (NUJ 2012, 2). The basic idea is that grants include OA publication fees that are used for funding journals and thereby publishing work. This argument neglects the problem of predatory business models that undermines the quality of academic work. Gold 
OA with author fees can result in new monopoly capital practices that do not necessarily guarantee the quality of editorial work, but quite likely threaten the quality of academic work. Such a union strategy neglects the need for OAJs that can ensure both the quality of editorial work and the quality of academic work.

\section{The Public Service and Commons Perspective: The Diamond Model of Open Access Publishing}

Peter Suber (2012) includes both for-profit and non-profit models as well as subsidized and APC-based models in the category of "gold OA|. We argue for differentiating the concept of Gold Open Access Publishing because Suber and others mesh together qualitatively different models, i.e. for-profit and not-for-profit ones, into the same category, whereas others, especially policy makers, simply forget or exclude not-for-profit models that do not use author fees or reader fees.

In the Diamond Open Access Model, not-for-profit, non-commercial organizations, associations or networks publish material that is made available online in digital format, is free of charge for readers and authors and does not allow commercial and for-profit re-use.

The fact that Diamond Open Access (DOA) has a digital format does not hinder that it is also made available in the form of printed publications in addition. We consider it as part of the model that publishers can charge for the actual printing costs without making monetary profits, but provide the digital version without charges. Publication "free of charge" means that neither authors nor individual readers nor institutions such as libraries have to pay for obtaining access to the literature published under the Diamond Open Access Model. Also authors or their institutions do not have to pay publication fees, article processing charges or other fees for getting articles published.

Using licenses such as Creative Commons (http://creativecommons.org/) allows Diamond Open Access publishers to enable others to reuse the works, share alike under the same terms, to either allow modifications of the works or not, and to prohibit commercial uses of works. If for example a Diamond Open Access journal uses an Attribution-NonCommercialNoDerivs Creative Commons License, others can copy, distribute, display and perform the work, must give the original author credit, may not use the work for commercial purposes, and may not alter, transform, or build upon the work. Creative Commons also provides license versions that enable others to commercially re-use materials. Such licenses are excluded from the Diamond Open Access Model because it is a strictly not-for-profit model, in which neither the publisher nor others derive monetary profits from a work.

Diamond Open Access is not just an idea, but rather, as the empirical data provided in this paper shows, the dominant reality of open access. This reality is however not enough acknowledged and taken into account in the open access journal debate. There is a danger that Diamond Open Access publishers' interests are overlooked and that a corporate model of OA will shape the future of academia. We therefore argue for a shift in the debate and that policy makers should take the Diamond Model serious by providing support for it.

We suggest that the other part of "Gold Open Access" - for-profit open access - is renamed Corporate Open Access: In the Corporate Open Access Model, companies, organizations or networks publish material online in a digital version, do so free of charge for the readers, but derive monetary profits with strategies such as charging authors or selling advertising space.

The use of the term Gold Open Access is confusing: whereas some include both Corporate and Diamond Open Access, others exclude Diamond Open Access. In the latter case, Diamond Open Access is defined out of existence, although - as empirical observations indicate - it seems to be the most important form of Open Access. Gold Open Access is an unclear and confusing term that does more harm than good. We therefore suggest to abolish it and to use the terms Diamond Open Access, Corporate Open Access and Green Open Access instead. This terminology can be supplemented by Peter Suber's (2012) distinction between gratis and libre OA as another dimension of classification. 
The suggested categorical differentiation has theoretical and policy purposes. It allows a clearer distinction of qualitatively different journals and opens up new policy perspectives. Corporate (non-open access) journal publishing creates the risks and realities of oligopolyand monopoly-practices and -pricing, exclusion from access for institutions, universities, libraries and individuals who cannot afford purchasing access, which not only implies unequal access, but is also a structurally-racist practice that disadvantages scholars and institutions in developing countries. It furthermore privatizes and commodifies academic knowledge that can best be discussed and used and have effects if it is available to anyone as a public or common good without paying for access. Corporate Open Access publishing bears the risk of the emergence of predatory publishing companies, the undermining of peer-review in order to make monetary profits, and the emergence of new academic inequalities, in which well-endowed institutions, research centres, department, faculties and individual scholars are able to pay publication fees and less well-endowed ones are excluded. This form of publishing results in new inequalities - not an inequality of reading access, but an inequality of publishing access. It is again very likely to be structurally-racist in character and to especially disadvantage scholars in developing countries. Therefore Diamond Open Access is the only sustainable future for academic publishing.

The cultural theorist Gary Hall argues that all academic knowledge should be made available in open access format. He discusses potential advantages: "Academics could provide their classes with as many copies of books and journal articles as they liked, simply by supplying students with an address where they can find them on the net and download them for free. By 'splicing and dicing' from other texts, tutors could even put their own readers together in this fashion, and ensure that they are constructed to suit the exact requirements of their specific courses [...] academics and researchers would no longer need to worry about whether their next project was going to appeal to a publisher as something that could be marketed and sold. [...] What is more, their text can remain available for as long as they wish - so they never again need to suffer the indignity of having their work go out of print after only eighteen months because their publisher only brought out a hardback book version, which cost $£ 50 / \$ U S 99$ a piece and which few people except institutional libraries could afford to purchase" (Hall 2008, 44f).

Hall furthermore argues that open access as "global public information commons", "in which access to knowledge and ideas is available to everyone who is connected to the Internet: rich and poor, privileged and underprivileged", "enables the breaking down of the barriers between the university and the rest of society, as well as between countries in the "developed' and 'undeveloped' worlds; and helps to overcome both the 'Westernization' of the research literature and what has been referred to as the 'digital divide' through the creation of a far more decentralized and distributed research community" (Hall 2008, 190).

Fostering Diamond Open Access requires policy measures and material support. A lot of taxpayers' money that universities receive as state funding and students' fees are today paid by libraries and universities to corporate publishing houses for buying journal subscriptions and purchasing books. In addition many research councils and funding institutions have publication schemes, to which scholars can apply for obtaining publication subsidies that are as a result to a specific degree paid to corporate publishers. This means that there is direct and indirect public funding of corporate publishing houses. Direct and indirect funding of corporate publishing should in our view be completely abandoned and legally forbidden because it supports monopoly-capitalist practices that disadvantage scholars and readers. We instead think it is feasible and necessary that innovative policy measures are taken that support the publishing of Diamond Open Access (DOA) journals and books:

a) Public funding models for Diamond Open Access (DOA) that enable such projects to employ editorial assistants, copyeditors, proof readers, designers, technicians, etc;

b) Mandatory funding-, research evaluation- and promotion-policies by research councils, higher education and research assessment institutions, universities, faculties and departments that only take Diamond Open Access (DOA) publications into account or give specific priority in reviews, promotions and research evaluations to such publications; 
c) Universities should implement policies that give special consideration to the work as editor, managing editor, reviewer or editorial board member for Diamond Open Access (DOA);

d) Substitution of the major role played by the Science Citation Index (SCl), the Social Sciences Citation Index (SSCl) and the Arts and Humanities Citation Index (AHCl) in many academic evaluations by the Directory of Open Access Journals (DOAJ).

e) All research councils in the world should introduce mandatory policies that regulate that scholars who receive funding are obliged to publish in Diamond Open Access (DOA).

Those who take what we have termed in this article the "union perspective" are likely to respond to our suggestions that the outcome will be further rationalization and layoffs of publishing workers employed by corporate publishers and university presses. These jobs are, as we have argued, however already today to a certain degree funded by public money. We are suggesting cutting out the middle person, which is a "corporate person", between publishing workers, authors and readers that today makes profits from public money. We suggest turning publishing work to a specific degree into public service jobs that are organized by nonprofit open access publishers, libraries in public universities and non-profit academic associations.

According to estimations, the median income in the USA of a full-time editorial assistant was US\$ 31853 in $2013^{7}$. The median income of a graphic designer was according to the same source US\$ 39259 . The median weekly earnings in the USA were US\$ 775 in July $2013^{8}$, which results in a median annual pay of US\$ 40300 . According to estimations, the median income of an editorial assistant in the UK was $£ 18355$ in $2013^{9}$. For a graphic designer the figure was $£ 19378^{10}$. In the UK, the median weekly wage in 2012 was $£ 505.9$ and therefore the median annual wage $£ 26306.8^{11}$. The data indicate that standard publishing jobs such as designers and editorial assistants are on average relatively low-paid jobs in both the UK and the USA. Turning publishing jobs increasingly into public service jobs via funding for Diamond Open Access (DOA) has the potential to improve the employment situation of publishing workers because public service- and commons-based employers have no need to cut wages in order to increase profits, as they do not have a for-profit imperative. Public-service open access production jobs are much less at risk of having to face bad working conditions, downsizing and lay-offs, outsourcing, overwork, underpayment, precarious work etc.

Taking Open Access serious can only be done by publicly funding DOA. If this is increasingly done, then it will bring about changes in the publishing industry that have a huge potential to benefit publishing workers, academic authors and readers/audiences.

\section{Conclusion}

We live in times of turbulence and change. The future of academia and academic publishing is likely to be different from how we know it today. There are both great opportunities and risks. The risk is that corporate interests continue to dominate academia and academic publishing. Corporate domination poses disadvantages for scholars, universities, libraries and publishing workers: the reality of academic publishing today is a predominance of large corporate publishing houses that reap high profits by charging oligopolistic prices for access to journals and articles and paying relatively low wages to publishing workers. The results are unequal and limited access to academic knowledge, the use of public funding for private publishers' profits, the commodification of the knowledge commons, and the exploitation of publishing workers. If the current condition continues, academia's future will look bleak. Discus-

\footnotetext{
${ }^{7}$ http://www.payscale.com/research/US/Industry=Publishing/Salary, accessed on September 5, 2013.

8 http://www.bls.gov/news.release/wkyeng.nr0.htm, accessed on September 8, 2013.

9 http://www. payscale.com/research/UK/Industry=Publishing/Salary, accessed on September 5, 2013.

${ }^{10} \mathrm{Ibid}$.

${ }^{11}$ What do you get paid? The 2012 UK salary survey results. The Guardian, November 22, 2012.

http://www.theguardian.com/news/datablog/2012/nov/22/pay-salaries-survey-ashe-ons
} 
sions about open access journal and book publishing intervene into the question of how the future of academia and academic publishing should look like.

We have argued in this reflection that not open access publishing in general, but a specific form of open access - the diamond model - should shape the future of academia and academic publishing. We have stressed that corporate open access that makes use of author fees or article processing charges is a further commodification of the academic world that if further advanced will result in new inequalities and predatory forms of publishing.

Academic knowledge production is the production and consumption of common knowledge: an author bases her/his ideas on existing knowledge and refers to this knowledge in the form of citations, bibliographic references, criticisms and discussions. This practice of referencing enables him/her to reflect on foundations that allow her/him to produce new knowledge that goes beyond the state of the art. Academic knowledge production can be interpreted as a communication process: each article, chapter, report or book addresses the public and other scholars as communicative subjects who are invited to respond. A new academic publication not only contains new knowledge that describes and reflects on the status of specific parts of the world, but also discusses previous knowledge. It communicates something back to the original communication and a broader knowledge community. Academic authors have the objective interest that their knowledge is available to all and that they do not have to pay for accessing other knowledge. Paying for access to knowledge seriously limits the possibilities of academic communication as well as academic knowledge production and circulation. In essence, academic knowledge is a common good: it is based on previous knowledge and is a foundation for future knowledge. A single article is not just an individual creation, it is the creation of the whole academic communication process, into which manifold contributors are involved over many years and ages.

The cultural theorist Raymond Williams $(1983,70-73)$ stressed the linguistic connection between the words "common" and "communication": that something is a common good means that it is "something shared" (Williams 1983, 71), it is "common to a community" (Williams 1983, 70). To communicate means to make information "common to many" (Williams 1983, 72). Communication and communications are part of the commons of society: they are fundamental needs, goods and processes necessary for the survival of humankind. Academic communication in the form of knowledge and discussions form a fundamental existential condition of the academic system as a whole. It is an academic common. Academic knowledge forms an important part of these commons.

The sociologist Robert Merton $(1988,620)$ has stressed the importance of the common character of academia and academic knowledge: "Institutionalized arrangements have evolved to motivate scientists to contribute freely to the common wealth of knowledge according to their trained capacities, just as they can freely take from that common wealth what they need. [...] In the commons of science it is structurally the case that the give and the take both work to enlarge the common resource of accessible knowledge".

The fact that corporate interests dominate academic publishing means that the academic commons have been privatized and commodified. What should be common property of all is in reality often the private property of corporate academic publishers, although this knowledge has historical and social character and has been produced by many academics in common.

Diamond open access (DOA) publishing is the opportunity to reclaim academic commons. It can realise the true essence of academia as a communication system that produces and communicates academic knowledge as a commons in an open process. Fostering academic commons through diamond open access (DOA) requires public funding, policies that base evaluations and research grants on the diamond model and a system of rewards for scholars who act as editors, editorial board members or reviewers for such publications.

Diamond open access (DOA) stands in the interests of both academic workers and publishing workers. The academic publishing houses' oligopoly profits are based on the exploitation of academic workers' free labour and publishing workers' paid labour. By transforming academic knowledge into commons and publishing work into public service jobs, the dia- 
mond model can solve both the problem of access to knowledge and the problem of job insecurity and precarious labour in academic publishing.

Policy makers, academics and publishing workers of all lands unite! Another academia is possible! Another academic publishing world is possible! Diamond open access publishing is possible!

\section{References}

Beall, Jeffrey. 2012. Criteria for Determining Predatory Open-Access Publishers. 2nd edition. http://scholarlyoa.com/2012/11/30/criteria-for-determining-predatory-open-access-publishers-2ndedition/ (accessed on September 8, 2013)

Bergstrom, Carl T. and Theodore C. Bergstrom. 2002. The Economics of Scholarly Journal Publishing. http://octavia.zoology.washington.edu/publishing/ (accessed on August 21, 2013).

Bergstrom, Carl T. and Theodore C. Bergstrom, Theodore C. 2004. Will Open Access Compete Away Monopoly Profits in Journal Publishing?

http://octavia.zoology.washington.edu/publishing/BergstromAndBergstrom04b.pdf (accessed on August 21, 2013).

Bergstrom, Carl T. and Theodore C. Bergstrom. 2006. The Economics of Ecology Journals. Frontiers in Ecology and the Environment 4 (9): 488-495.

Darnton, Robert. 2010. The Case for Books. New York: PublicAffairs.

European Commission. 2012. Towards Better Access to Scientific Information: Boosting the Benefits of Public Investments in Research.

http://ec.europa.eu/research/science-society/document_library/pdf_06/era-communication-towardsbetter-access-to-scientific-information_en.pdf (accessed on September 8, 2013)

Hall, Gary. 2008. Digitize this Book! The Politics of New Media, or Why We Need Open Access Now. Minneapolis, MN: University of Minnesota Press.

International Association of Scientific, Technical \& Medical Publishers. 2013. Publishers Support Sustainable Open Access. http://www.stm-assoc.org/publishers-support-sustainable-open-access/ (accessed on July 4, 2013).

Merton, Robert K. 1968. The Matthew Effect in Science: The Reward and Communication System of Science are Considered. Science 159 (3810): 56-63.

Merton, Robert K. 1988. The Matthew Effect in Science, II: Cumlative Advantage and the Symbolism of Intellectual Property. ISIS 79 (4): 606-623.

National Union of Journalists. 2012. Open Access Journals and Editorial Quality. http://www.nuj.org.uk/files/Final open access NUJ briefing.pdf (accessed on July 4, 2013)

Research Councils UK (RCUK). 2012. RCUK Policy on Open Access and Supporting Guidance. http://www.rcuk.ac.uk/documents/documents/RCUKOpenAccessPolicy.pdf (accessed on September 8, 2013).

Sandoval, Marisol and Christian Fuchs. 2010. Towards A Critical Theory of Alternative Media. Telematics and Informatics 27 (2): 141-150.

Suber, Peter. 2012. Open Access. Cambridge, MA: The MIT Press.

Suber, Peter. 2013. A Misleading Survey. https://plus.google.com/109377556796183035206/posts/K1UE3XDk9E9 (accessed on September 8, 2013)

Thomson Reuters. 2008. Whitepaper: Using Bibliometrics: A Guide to Evaluating Research Performance with Citation Data.

http://interest.science.thomsonreuters.com/forms/Verify?doc=http://science.thomsonreuters.com/m/ pdfs/325133 thomson. pdf\&rt=Marketing\&sbu=SSR\&cid=70170000000I52W\&cn=2008-AGBiblioWhitePaper\#1 (accessed on September 8, 2013)

UK Publishers Association. 2012. The Publishers Association Comments on Release of the Finch Report on How to Expand Access to Research Publications.

http://www. publishersassociation.org.uk/index. php?option=com content\&view=article\&id=2265: the -publishers-association-comments-on-release-of-the-finch-report-on-how-to-expand-access-toresearch-publications\&catid=503: pa-press-releases-and-comments\&ltemid=1618 (accessed on September 8, 2013) 
Walters, William H. and Anne C. Lindvill. 2011. Characteristics of Open Access Journals in Six Subject Areas. College \& Research Libraries 72 (4): 372-392.

Williams, Raymond. 1983. Keywords. A Vocabulary of Culture and Society. New York: Oxford University Press.

Working Group on Expanding Access to Published Research Findings. 2012. Accessibility, Sustainability, Excellence: How to Expand Access to Research Publications.

http://www.researchinfonet.org/wp-content/uploads/2012/06/Finch-Group-report-FINALVERSION.pdf (accessed on September 8, 2013)

Wyly, Brandon J. (1998) Competition in Scholarly Publishing? What Publisher Profits Reveal. ARL Newsletter No. 200.

http://staff.washington.edu/tabrooks/510.course/ARL/CompetitionPublishing.htm (accessed on August 21, 2013).

\section{About the Authors}

Christian Fuchs

is professor of social media at the University of Westminster's Communication and Media Research Institute (CAMRI) and the Centre for Social Media Research. He is editor of the open access journal tripleC: Communication, Capitalism \& Critique.

Marisol Sandoval

is a lecturer at City University London's Centre for Cultural Policy and Management. She is managing editor of the open access journal tripleC: Communication, Capitalism \& Critique. 